This is a self-archived version of an original article. This version may differ from the original in pagination and typographic details.

Author(s): Jameel, Tanzeela; Ali, Rukhsana; Malik, Kamran Ahmed

Title: Social Media as an Opinion Formulator : A Study on Implications and Recent Developments

Year: 2019

Version: Accepted version (Final draft)

Copyright: (C) IEEE 2019

Rights: In Copyright

Rights url: http://rightsstatements.org/page//nC/1.0/?language=en

Please cite the original version:

Jameel, T., Ali, R., \& Malik, K. A. (2019). Social Media as an Opinion Formulator : A Study on Implications and Recent Developments. In iCoMET 2019 : 2nd International Conference on Computing, Mathematics and Engineering Technologies. IEEE.

https://doi.org/10.1109/ICOMET.2019.8673509 


\title{
Social Media as an Opinion Formulator: A Study on Implications and Recent Developments
}

\author{
Tanzeela Jameel*, Rukhsana Ali ${ }^{\dagger}$, Kamran Ahmed Malik \\ * Faculty of Social Sciences, University of Balochistan, Quetta, Pakistan. \\ $\dagger$ Faculty of Humanities and Social Sciences, University of Jyväskylä, FI-40014 Jyväskylä, Finland. \\ $\ddagger$ Sukkur IBA University, Sukkur, Pakistan. \\ Email: tanzilajameel26@gmail.com
}

\begin{abstract}
Social media has a great influence on how information reaches us and how we form an opinion based on it. For many users, social media increases the variety of information and ensure its accessibility across different platforms. However, recent years have seen an exponential increase in the power of social media. Most often, the forwarding and sharing of journalistic articles serve the recommendation from the user's point of view, but recently, these platforms have been developed into an echo chamber to transport additional information or even a critical attitude. In addition, the uncontrolled influx of social media in different parts of the world favors phenomena such as fake news and social bots. These threaten the exchange of views sought by mutual understanding and sincerity that democratic societies need. Motivated by these observations, this article aims to paint a realistic picture of the impact of social media. To do so, we discuss the recent developments and social changes and provide analysis of the global impact of the connected audience. Next, we shed light on some of the opinion formulation procedures and its key enablers. Finally, we present an explanatory discussion on the Facebook algorithms and provide two case studies in the wake of recent global events.
\end{abstract}

\section{Index Terms}

Democratic societies, Connected audience, Facebook algorithms, Fake news, Social media.

\section{INTRODUCTION}

In recent years, the role of two social events in the media has ensured that political debate has little impact: the British vote for Brexit and the election of Donald Trump as US President [1], [2]. These were also relatively small decisions that turned out differently from what had been predicted by debaters in advance. What resulted this sudden shift in the decision? What are the odds that these results were already deterministic? These questions have been raised several times since the both elections. However, in the search for explanations, the term "social media" came up again and again [3].

It is said that the Brexit advocates actively used social media to spread misleading information about the alleged advantages of the EU's exit, which may have convinced the Brexit voters. Similarly, Donald Trump, whom some refer to as the "Twitter president", not only used the short message service as an electoral instrument, but remained faithful to his line after taking office, bypassing the established media (that he constantly vilified as a "fake media") directly to a million people [4], [5]. A graphical illustration of occurrence frequency of the terms "Brexit Negotiations" and "Donald Trump" is presented in Fig. 1 These trends have also prevailed in some other parts of Europe. The parliamentary or presidential elections in the Netherlands, France, and Austria, for example, were all dominated by a hard debate with populist candidates, which also took place on social media.

This article highlights the impact of social media on building opinions. More specifically, we reveal the complex relationship of the Internet and the public. We identify how the technical mediation paves the way to spread misleading information through connected audience. We also present a bird's eye view of the Facebook algorithm and explain how it connects more than 25\% of the human being on the Earth every day. In the end, we provide two case studies of the recent times: (1) Dresden rallies and (2) chatbot leo.

The remainder of the paper is organized as follows. Section II discuss the recent developments and social changes in the era of the Internet. Section III provides analysis of the global impact of connected audience. Section IV highlights the opinion formulation enablers and procedures. Section V presents a discussion on the Facebook algorithms which is followed by Section VI that provides two case studies. Finally, Section VII concludes this work.

\section{The InTERnet AND The Public}

The Internet continues this interconnected development of the technological and social change. It provides a further technological basis for the dissemination of information. Mass media organizations also take advantage of this opportunity. They meet the characteristics of the professional economic journalism, including, for example, certain standards of research and the treatment of information in journalistic text types such as reports [6]. In addition, hopefully, they all adhere to ethical standards of journalism, including a commitment to truth, neutrality, and balance in reporting. But, the Internet also allows ordinary users to spread information and potentially reach a large audience. Some see the era of "citizen journalism", in which every 


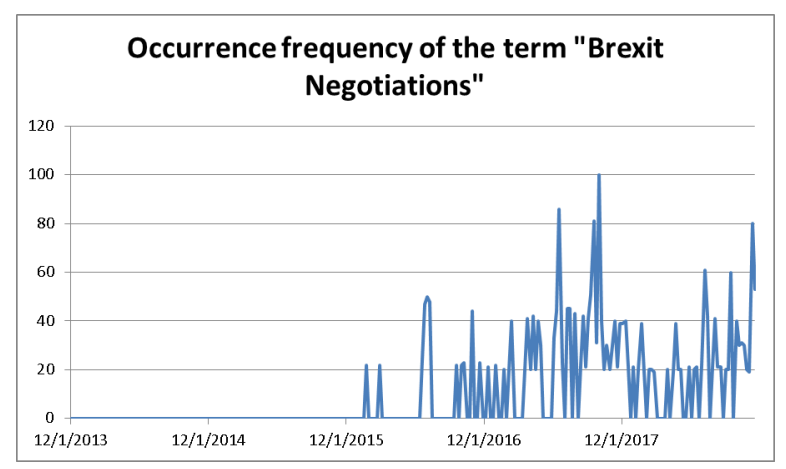

(a)

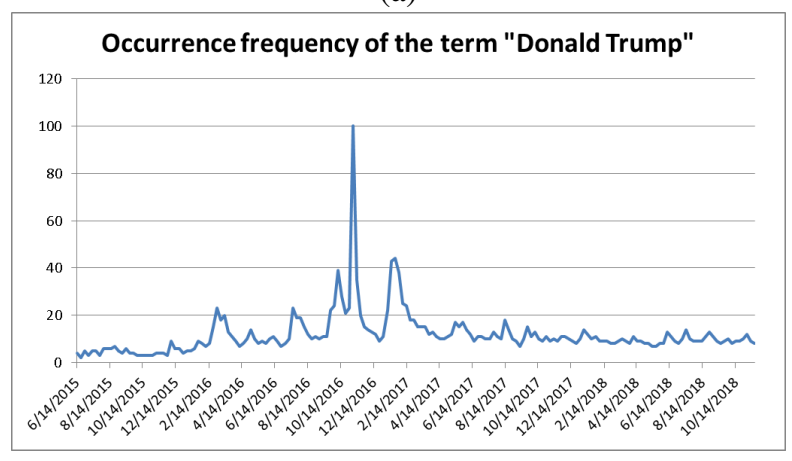

(b)

Fig. 1. Comparison of word occurrence frequency in Google search for the terms (a) Brexit Negotiation (b) Donald Trump.

citizen can report on the events around them thanks to a digital camera and Internet access. But is that true? Do social media make us all journalists?

The short answer: no. The slightly longer answer: No, people do not automatically become journalists when they use social media. However, journalism loses its monopoly on preparing information and making it publicly available [6]. Thanks to the internet and social media, the media public is no longer based solely on journalistic mediation, but also on participatory and technical mediation. The individual steps of this mediation can clearly show how the foundations of media publicity expand. The special feature of personal public relations is that information is selected and prepared according to criteria of personal relevance. This includes a focus on the subjective portrayal and evaluation of events or topics, as opposed to the journalistic achievements.

\section{A. Personal Opinions}

Personal opinions also follow other criteria when it comes to preparing and presenting the topics. Because personal opinions are designed for conversion and exchange, we often find written language that closely resembles the spoken word. It contains colloquial phrases or slang, own shortcuts and emoticons like the "Smilie". Such forms cannot be found in journalistic texts. In all this, as in journalism, there is a fundamental claim to genuineness. While it is all about factual truth, truthfulness stands in the forefront of the personal opinion sphere. Users expect each other that no one pretends to be someone else, that one is not deceiving or lying, in short: that one gives oneself authentically. The contrast is the fake profile created with insincere or even malicious interests.

The technical infrastructure, i.e., the software programs, platforms and services of the Internet and the social media, bring additional mechanisms and criteria of mediation into play. The continuously growing wealth of information on the Internet, to which both journalistic media and personal public alike contribute, can only be tapped with the help of such technical aids [6]. This is why innumerable services and programs are in use that automatically, continuously and partly in real time capture, systematize, categorize, catalog and archive the informational world of the Internet.

Based on these technical operations that to the public media and journalism are invisible most users, databases are created, which are not available in their entirety. Instead, the users of relevant information services - which can be general search engines, but also specialized portals - decide only through their search queries, which keywords or topics information from the abundance selected and presented. However, the developers and operators of the relevant information service determine beforehand which sources are recorded and in which form the corresponding data is stored. On the one hand, they determine 
the accessible section of the world. On the other hand, by programming the sorting algorithms, they also determine how information about a topic or query is ordered and displayed.

\section{B. Technical Mediation}

This aspect is very important to understand the peculiarity of the extension of media publicity through social media. Quite different from personal opinion, and more so than journalism, technical mediation seems to follow objective and neutral criteria. But these criteria, which are expressed in programmed search, filter and sorting rules, do not fall from the sky but are deliberately designed that way.

In this way, the aspect of relevance also comes into play in technical mediation: journalists check events for certain news factors (is it current, does it affect many people, does someone have a prominent position, etc.) and, on this basis, decides whether they post a message or not. Search and sort algorithms have their own criteria. Google, for example, does not throw out all the web pages you've ever collected that contain the search term. Rather, a multitude of criteria are examined in fractions of a second: How often does a term appear on a website? If the page in the past frequently been updated public figure? And very important: Do many other pages point to the page in question? The idea behind this is that a link can be understood as a kind of "voice" for the corresponding landing page. A single page is therefore considered to be all the more relevant - and will tend to be higher or higher in search queries - the more other pages link to it.

Even on social media, on Twitter, YouTube or Facebook, we can search for specific terms or topics across the platform. But there are two other features that determine whether and how information is displayed to a user: timeliness and social proximity. The latter is determined by whether another person, a company, a media offer or a party belongs to my contacts. Taken together, this creates the particular form of publicity that social media creates: information is not delivered to individuals as packages of news items that are selected, edited and bundled at specific times according to journalistic criteria [6], [7]. No one would say, "Oh, it's 8 pm, we have to watch Twitter's evening news". Rather, we find in the social media a constantly updated and personalized stream of news that is determined by which sources we have previously used. All in all, these algorithmically controlled flows of information contribute to "real-time web": we can get an impression of what is happening right now, or at least in the last few hours, in our environment. The establishment of contacts and the maintenance of friendship or business relationships, thus, also have elements of information management [8].

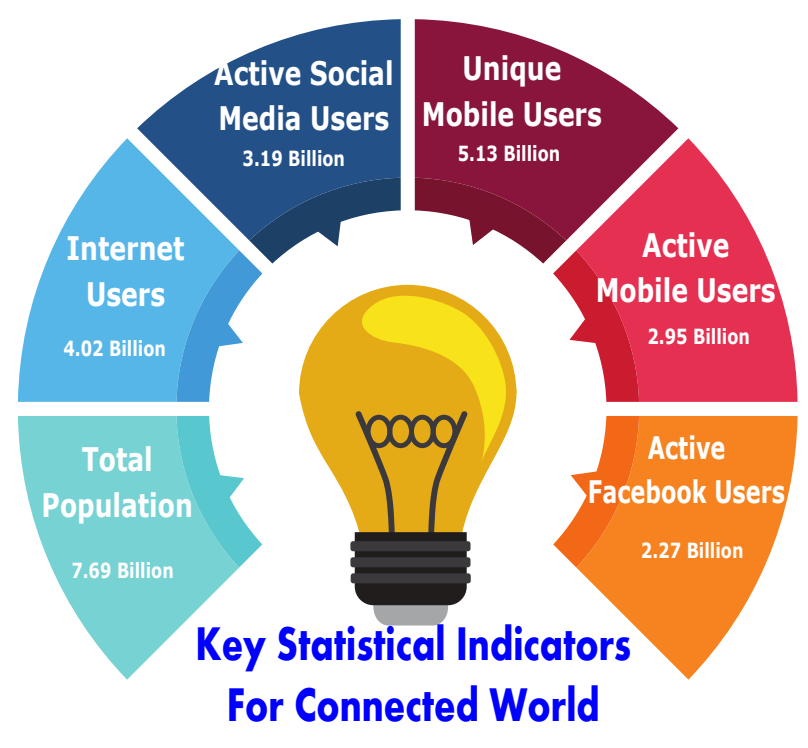

Fig. 2. Statistical indicators of connected world as per January 2018.

\section{Connected Audience}

This section discusses the influence of social media on connected audience. The term connected audience refers to the amount of people using the Internet and social media services for social interactions. Fig. 2 shows some of the key indicators of the connected world. One can observe that the more people are connecting through the Internet each day, partly because of rapid influx of smart phones and mobile devices. In this regard, it is worth highlighting that the "connected audience" of social media are held together by three types of links.

- They rely on the exchange of data between interconnected computers. 
- They emerge in social networks, that is, in networks of human relationships of varying degrees of closeness and closeness.

- They are based on linking information and text of all kinds, be it through hyperlinks, through the sequence of text and comments, or through the links in a database.

These links have different impact on the audience, as discussed on below-mentioned subsections:

\section{A. Communication Impact on Connected Audience}

In recent years, the number of journalistic offerings that operate their own profiles and accounts in the social media has increased rapidly. They populate Facebook pages with their contents, point out new articles via their own Twitter accounts or maintain editorial web blogs. By doing so, users can add the media offer to their own "radar" and keep up to date on new articles in the daily show.

As many users independently disseminate information, an indication of an article, or the link to a spectacular video, a large number of people can be reached quickly. Especially in advertising and marketing, one speaks of "viral effects" in this context, because the distribution within a network follows similar patterns as the contagion in epidemics [9]. Unlike influenza, however, dissemination is certainly desired here and is even aimed at through targeted campaigns. For example, a company may produce special websites or commercials in the hope that users will continue to recommend them in social media.

\section{B. Spreading of Misleading Information}

Misleading or clearly wrong information can spread thanks to social media. On Facebook, for example, there is a picture that Angela Merkel is showing with a young Syrian, who is sometimes referred to as the alleged assassin of the Brussels terrorist attacks of March 2016, and as a co-perpetrator of a homicide attempt on a homeless man in Berlin. In fact, it is a selfie made by a respectable Syrian refugee with the Chancellor. But many users do not take notice of this correction, but rather pass on the photo, along with its false and manipulative context.

In the public discussion is in connection with such events mostly by "fake news" the speech [10]. But rightly, the term is now considered too spongy to be really helpful. The reasons why misleading information is created and fed into the network of social media can be quite different. Conspiracy theories or politically motivated propaganda that deliberately portray facts only selectively or incorrectly are something other than "click bait", which works on the pattern: "10 exciting insights into XYZ" that have hitherto been concealed [11]. These are lurid headlines and sensational announcements just the hanger to attract users and then make money on the ads shown. This, in turn, distinguishes messages that satirically exaggerate or parody common misstatements - but at times are taken by people at face value. And finally, the case cannot be ruled out that even in the case of thorough journalistic research, mistakes can creep in or facts are put in the wrong light.

Distinguishing these variants of misleading information is also important because it requires different strategies to counteract them. In general, the distribution of factually false information on platforms such as Facebook or Twitter is initially difficult to suppress because there is no central instance of the editorial control, but the users themselves decide on the posting and redistribution of content. Some people, more than others, tend not to question information if it fits in with their established view of the world. Against this background, Facebook announced at the end of 2016 that it would be more proactive against misleading information and, for example, filter out click bait using algorithmic methods. In regard to other forms of "Fake News", the platform is now working with external "fact-checking" organizations together to the corresponding posts as "controversial" to mark [10]. And outside of Facebook, websites like www.mimikama.at, www.hoaxmap.org or www.faktenfinder.tagesschau.de are confronted with numerous cases of false reports and provide them with verified information.

\section{Social Media: A Catalyst of Change}

What is new about the social media, however, is that it makes communication comprehensible to others. What was discussed at the evening table, in the cafe or in the schoolyard, people now also share in the comment areas on a Facebook post or on Twitter? Journalists who observe these conversations can quickly gain an impression of the resonance that their work finds: the public make criticism and need for corrections of articles, but also an enjoyment of a successful presentation or criticism of neglected topics visible. Journalists can react to this, engage in discussions or correct points of criticism. The communication modes of "publishing" and "conversation", mainly separated under mass media conditions, largely coincide.

But we must not underestimate the fact that significantly increased effort for journalistic editors means integrating social media into one's own work. It is no coincidence that independent editorial roles have emerged in the meantime. These include, for example, the "community manager" or the "social media editor". They make it clear that maintaining profiles in social media, observing and communicating with the public can no longer just be done on the side. On the one hand, notorious poly-commentators and cynical mobsters are bustling in social media. On the other hand, there are also experts who have more knowledge of individual topics than journalists, or clever minds who add further valid arguments to a discussion. 


\section{MEDiA AND OPINION}

Obviously, the changes in publicity and journalistic work had a significant influence on forming an opinion on socially relevant topics. In order to be able to better describe and understand this influence, it is helpful to ask which role social media offers for the formation of opinions by people.

\section{A. Sharing Knowledge}

It is important for the media to convey knowledge, that is, to provide information on specific issues. These can vary in depth and people will receive some of this information as casual or unplanned, while others will search for and research it. All of this, however, results in the fact that the media offers to help us to obtain facts about the world around us, which we can not win from our own point of view. They assume the role of "putting issues on the agenda". Media thus convey to us which events or concerns are of social relevance. When many media outlets report about the development of refugee numbers, people will find this topic important and urgent.

\section{B. Agenda Setting}

This agenda setting function, as it is called in the field of communication science, is closely linked (but not congruent) to "framing" - i.e., the embedding of information on a topic in superordinate contexts or interpretations. For example, reporting on rising (or declining) numbers of refugees may highlight the humanitarian aspects and the desperate situation in civil war countries or address the financial costs and implications for receiving cities and towns. Depending on the accentuation, the assessments that people receive as a result of reporting may also change.

\section{Collective Forum}

Media also help us to develop a sense of dissemination of different opinions in society. We can win with their help not only an insight into the variety of possible attitudes to answer different question but also the social "planning climate" and make ourselves whether we determined our view to Subjects tend to be in the minority or to the general consensus - this has also been described more generally as the "forum function" of the journalistic media. These forums can also act as social media platforms to promote value based business model [8], as illustrated in Fig. 3 .

The above-mentioned aspects concern the prerequisites for forming opinions, because - at least in the ideal case - they are based on the knowledge of certain facts, an assessment of their relevance and the knowledge of different attitudes. There are situations in which media directly influence attitudes or trigger impulses for action [11]. Prototypical forms of such persuasive communication include election campaigns or fund-raising. In many cases, however, the actual formation of opinions, i.e., the formation, stabilization or change of my own attitude to a dispute or a topic, only takes place in an exchange with other people: in discussions within the family, with friends or on the sidelines of political rallies. In many cases, we also rely more on information and are more likely to be persuaded by opinions when they come from our social environment, especially when we perceive the relevant persons as opinion leaders.

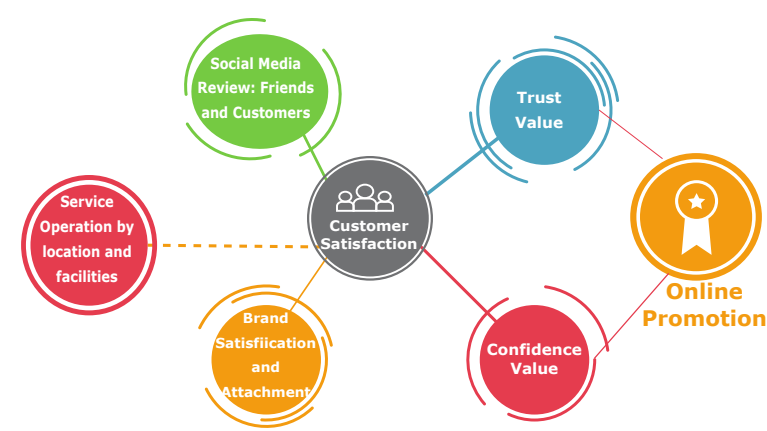

Fig. 3. Value based business model and conceptual loyalty in the era of social media.

\section{Potential Restrictions on Diversity}

The scenario is known as "filter bubble" has presumably gained most prominence. Users of social media would not perceive the variety of information available in principle, but would be limited in their view of the world. This is due to three interdependent factors rooted in psychological, sociological and technological contexts [12].

In addition, we humans - individually more or less pronounced - have a penchant for opinion, rather than constantly exposing us to conflicting information [13]. We also tend to keep information better if it fits into our worldview. All of this serves to 
avoid "cognitive dissonance", as psychological research calls it [14]. There are also sociological mechanisms, so features of our social embeddedness and networks of relationships [12]. People tend to surround themselves with friends and acquaintances who are similar to themselves - for example, in terms of age and education, but also on interests, lifestyles or political views. We know this circumstance, which sociology calls "homophilia".

\section{A. Understanding Facebook's Selection Steps}

These characteristics of individual information processing and social embedding are to be understood as tendencies that are not equally pronounced in every human being and that can sometimes be suspended in individual situations. However, in social media, they encounter technical mechanisms that can exacerbate their effects. After all, intermediaries also offer an unmanageable amount of information, so they have to provide their users with a selection. This choice can be applied in two places, namely, the selection of sources that feed my own personal flow of information, and second, the highlighting or prominence of individual content in this constantly updated stream of information. Mechanisms of algorithmic filtering, recommending and personalizing play an important role in both selection steps, as can best be seen from the example of Facebook [15].

The first selection step is based on adding or choosing other people to a Facebook contacts, pages of companies, citizens' initiatives, celebrities, political parties, etc., like to subscribe to their news [16]. The basis for these suggestions is the rich data that Facebook has about existing network of relationships as well as preferences and activities. Every click and every "like" leaves a trail of data in which the mechanisms of selection described above are reflected [17]. That's why Facebook's suggestions are often strikingly accurate - and they also increase the chance to use Facebook, leaving more data traces behind. This again raises the problem of information overload, because in many cases, the information flow is only too extensive from that one could meaningfully perceive it entirely. For some years, Facebook has been using algorithms to filter this "news feed" and to weight content in it.

The parameters that determine this selection have been changed over and over again over the years and are not published in detail. But the closeness to another contact, measured in terms of the frequency with which one has interacted with another person in the past, as well as the similarity to other content that one has paid attention to in the past, seems to play an important role [18], [19]. Thus, over time, intermediary users move, partly through their own actions and partly through structural-technical framework conditions beyond their direct control, into increasingly personalized "filter bubbles". Consistently coming to an end, people in such filter bubbles are no longer aware that there are other topics or contrary views than those that have circulated in the past within one's own reference group.

\section{B. Social Media as the Echo Chamber}

In the case of social media, not only the information that users see is limited by the interplay of psychological, sociological and technical factors, but also the variety of opinions [12]. As a result, Facebook, YouTube or other intermediaries would not promote the exchange of conflicting arguments on socially relevant issues. Rather, there would be a reciprocal reinforcement of already preconceived opinions, under some circumstances even the "swaying" of ever more shrill and extreme voices, such as a self-reinforcing echo that does not make room.

This suggests that intermediaries restrict the variety of information, whereby the subject of the filter-bubble thesis is the information repertoires of an individual, while the echo-chamber thesis refers to the exchange of opinions. But if the multiplicity of information is replaced by the fragmentation and polarization of secluded groups, important pillars of social cohesion would be undermined, namely the knowledge of what issues and views exist in other parts of the population, coupled with the readiness to take conflicting information and weigh up counter-arguments to one's own position [4].

\section{CAse Studies}

In this respect, the aforementioned scenarios are indeed threatening - although it is far from fully understood to what degree which groups of people are actually in filter bubbles or echo chambers in relation to which topics. For example, studies show that a large proportion of the users have access to a variety of information repertoires on socially relevant topics and, as a result, are also confronted with contrary opinions and information. It is undeniable, however, that there are groups on Facebook and Twitter that represent certain worldviews or ideologies, shy away from conflicting information and are more susceptible to misinformation if they confirm their view of the world.

\section{A. Dresden Rallies}

Corresponding studies are available for supporters of conspiracy theories as well as populist or politically extreme groups. The Facebook page of Pegida, which was created in Dresden, played an important role in 2015 for the consolidation of the movement and the mobilization for rallies beyond Dresden. In a short time, numerous offshoots of the movement in other cities, as well as related Facebook groups, were created in which people unlawfully spread false reports and incited to insults and incitement to refugees and immigrants, the Federal Government and the "lying press". At least these developments have 
triggered a broad public debate on forms of hate speech in social media and their connection with political populism and extremism. Legal requirements (for example, the right to privacy) have always set limits to the freedom of expression on the Internet. But this does not seem to prevent some people from insulting, abusing, or denigrating individual people or whole groups of people in posts and comments - sometimes under their real name.

Against this backdrop, in the summer of 2016, in response to growing political pressure, a number of large providers (Facebook, YouTube, Twitter, and Microsoft) agreed with the EU on a "Code of Conduct" and the associated commitment, at least certain forms of hate Speech stronger combat. According to first reports, the speed at which reported contributions are checked and removed from the network has subsequently increased. Also, the above-mentioned Facebook page of the Dresdner Pegida Group was finally closed in the summer of 2016. But just the messages that users make themselves, so far obviously mostly rejected. In June 2017, the German Bundestag adopted the (Network Enforcement Act), which obliges platform operators to impose fines that are much more stringent and expedited, with the threat of high fines. However, it is questionable whether the law will endure before the Federal Constitutional Court. According to many experts, there is a risk that operators will not only extinguish actual hate speech but also, on a large scale, those contributions that are still covered by the right to freedom of expression.

\section{B. Chatbot Leo}

A recent phenomenon associated with the relevance of social media for opinion formation is the growth of automated profiles. Especially on platforms such as Facebook and Twitter, a growing operated send number of accounts not by people but by software programs. Such "bots" publish contributions independently according to predefined criteria or react to previously defined remarks by others [1]. In the form of news bots, for example, they can help users to orient themselves by automatically finding and bundling content for specific keywords from different sources. Chatbots are also conceivable, which respond to questions from users and refer to sources that, for example, carry political views of a party on. In the spring of 2017, for example, the CSU provided the chatbot Leo on Facebook - and earned recognition for this innovative tool of political communication as well as criticism, because many of Leo's replies to the comparatively blunt mockery of the political opposition did not go out.

In general, for these variants of bots, their use does not raise fundamental concerns provided they are programmed technically efficiently and do not produce faulty outputs. Much more critical are social bots that masquerade as normal users and automatically produce content, for example, to simulate high popularity for certain viewpoints or parties. Ultimately, they are propaganda tools that attempt to manipulate public debates and violate ethical communication principles, in particular, the norm of truthfulness. For this reason, many platforms also prohibit the use of social bots in their general terms and conditions, without, however, being able to completely rule out that such tools are currently active.

\section{CONCLUSION}

Despite aforementioned arguments, it is too early to give a conclusive and exhaustive answer to the impact that social media. In general, it is undeniable that the interplay of algorithmic selection and filtering mechanisms with general psychological and sociological patterns leads to a significant change in the flow of information. However, filter bubbles and echo chambers do not necessarily arise due to the variety of information increase for every user. Rather, as we have discussed earlier, both effects are possible and empirically detectable. Therefore, it depends heavily on the peculiarities of topics and user groups where social media has little to no opinion formation.

\section{REFERENCES}

[1] M. Bastos and D. Mercea, "The public accountability of social platforms: lessons from a study on bots and trolls in the brexit campaign," Phil. Trans. R. Soc. A, vol. 376, no. 2128, p. 20180003, 2018.

[2] G. Enli, "Twitter as arena for the authentic outsider: exploring the social media campaigns of trump and clinton in the 2016 us presidential election," European Journal of Communication, vol. 32, no. 1, pp. 50-61, 2017.

[3] F. Jameel, M. A. A. Haider, and A. A. Butt, "Security in SWIPT with Power Splitting Eavesdropper," Advances in Science, Technology and Engineering Systems Journal, vol. 2, no. 3, pp. 384-388, 2017.

[4] C. R. Sunstein, \# Republic: Divided democracy in the age of social media. Princeton University Press, 2018.

[5] F. Jameel, M. A. A. Haider, and A. A. Butt, "Secure Path Selection under Random Fading," Advances in Science, Technology and Engineering Systems Journal, vol. 2, no. 3, pp. 376-383, 2017.

[6] A. Bruns, Gatewatching and news curation: Journalism, social media, and the public sphere. Peter Lang, 2018.

[7] F. Jameel, M. A. A. Haider, A. A. Butt et al., "Performance assessment of satellite-terrestrial relays under correlated fading," in 2017 Fifth International Conference on Aerospace Science \& Engineering (ICASE). IEEE, 2017, pp. 1-6.

[8] U. Ramanathan, N. Subramanian, and G. Parrott, "Role of social media in retail network operations and marketing to enhance customer satisfaction," International Journal of Operations \& Production Management, vol. 37, no. 1, pp. 105-123, 2017.

[9] A. Hough, M. Bryce, and S. Forrest, "Social media and advertising natural contraception to young women: the case for clarity and transparency with reference to the example of natural cycles," BMJ Sex Reprod Health, vol. 44, no. 4, pp. 307-309, 2018.

[10] H. Allcott and M. Gentzkow, "Social media and fake news in the 2016 election," Journal of Economic Perspectives, vol. 31, no. 2, pp. 211-36, 2017.

[11] H. Kizgin, A. Jamal, B. L. Dey, and N. P. Rana, "The impact of social media on consumers acculturation and purchase intentions," Information Systems Frontiers, vol. 20, no. 3, pp. 503-514, 2018. 
[12] M. L. Birnbaum, A. F. Rizvi, C. U. Correll, J. M. Kane, and J. Confino, "Role of social media and the i nternet in pathways to care for adolescents and young adults with psychotic disorders and non-psychotic mood disorders," Early intervention in psychiatry, vol. 11, no. 4, pp. 290-295, 2017.

[13] V. Goodyear, K. Armour, and H. Wood, "The impact of social media on young peoples health and wellbeing: Evidence, guidelines and actions," 2018.

[14] C. M. Pulido, G. Redondo-Sama, T. Sordé-Martí, and R. Flecha, "Social impact in social media: A new method to evaluate the social impact of research," PloS one, vol. 13, no. 8, p. e0203117, 2018.

[15] M. Carlson, "Facebook in the news: Social media, journalism, and public responsibility following the 2016 trending topics controversy," Digital Journalism, vol. 6, no. 1, pp. 4-20, 2018.

[16] S. A. Salloum, M. Al-Emran, A. A. Monem, and K. Shaalan, "A survey of text mining in social media: facebook and twitter perspectives," Adv. Sci. Technol. Eng. Syst. J, vol. 2, no. 1, pp. 127-133, 2017.

[17] D. Lee, K. Hosanagar, and H. S. Nair, "Advertising content and consumer engagement on social media: evidence from facebook," Management Science, 2018.

[18] S. Jones, M. Heise, and H. Osler, "Social media and its impact," Proceedings for Mediated Minds 2018, vol. 1, no. 1, 2018.

[19] D. N. K. J. Arachchilage, F. Jameel, and M. Qaraqe, "Secure rf energy harvesting scheme for future wireless networks," in Qatar Foundation Annual Research Conference Proceedings Volume 2018 Issue 3, vol. 2018, no. 3. Hamad bin Khalifa University Press (HBKU Press), 2018, p. ICTPP179. 